Disclosure of Interest: None declared

DOI: 10.1136/annrheumdis-2018-eular.7251

\section{AB1043 1 THE CLINICAL PROFILE OF GOUT SIGNIFICANTLY DIFFERS BETWEEN MALE AND FEMALE}

R. te Kampe ${ }^{1}$, C. van Durme ${ }^{1}$, M. Janssen ${ }^{2}$, A. Boonen ${ }^{1}$, T. Jansen ${ }^{2}$. ${ }^{1}$ Rheumatology, Maastricht University Medical Center, Maastricht, ${ }^{2}$ Rheumatology, VieCuri Medical Center, Venlo, Netherlands

Background: Gout, the most common type of inflammatory arthritis, is considered as a predominant male disease. Notwithstanding, there is an increased risk of gout in female after the menopause.

Objectives: Our objective was to assess differences in the clinical features between female and male patients.

Methods: Data of newly diagnosed gout patients attending the rheumatology outpatient clinics of one secondary and one tertiary i.e. university centre in the south of the Netherlands were used. We compared baseline characteristics of males and females regarding to demographics, BMI, presence of tophi, medication use (diuretics, prophylaxis of gout and uric acid lowering drugs), serum and urine concentration of uric acid and creatinine, and comorbidities. Additional, fractional excretion of uric acid (FEUa), calculated as (urinary uric acid $x$ serum creatinine)/ (serum uric acid $x$ urinary creatinine), was compared. FEUa gives the percentage of uric acid renally filtered and thus excreted in the urine (normal range $7 \%-12 \%$ ). Independent t-tests and chi square were used to assess differences between females and males statistically.

Results: 66 female (16.6\%) and 331 male (83.4\%) patients with gout (MSU crystals 60.6 vs $68.6 \%$, respectively) were included. At baseline, females compared to males had a significantly higher age $(73 \pm 12$ vs $63 \pm 13$ years, $\mathrm{p}<0.001)$, BMI $(30.1$ \pm 5.2 vs $28.7 \pm 4.7 \mathrm{~kg} / \mathrm{m}^{2}, \mathrm{p}=0.034$ ) and diuretic use (63.6 vs $\left.27.8 \%, p<0.001\right)$. Females had also a significantly higher percentage of comorbidities, including hypertension ( 77.3 vs $59.5 \%, p=0.003$ ), diabetes ( 48.5 vs $22.7 \%, p<0.001$ ) and chronic kidney disease (eGFR of $46.4 \pm 24.2$ vs $62.5 \pm 22.9, \mathrm{p}<0.001$ ). There was no significantly difference in serum and urine uric acid concentration, current urate lowering and prophylactic medication, presence of tophi and nephrolithiasis. Also, the FEUa was similar in females vs males $(5.1 \pm 3.0$ vs $4.4 \% \pm 1.7 \%, p=0.201)$.

Conclusions: The clinical profile of gout in females significantly differs compared with males: significantly older, more advanced decrease in renal function and higher prevalence of hypertension in the females. As Dutch guidelines recommend starting with a diuretic for the treatment of hypertension in patients aged 70 + ; this may have a role in explaining the higher numbers of females using diuretics. The start of diuretics has previously been associated with hyperuricemia and increases the risk of gout in the female population. Although diuretic use has proven to be a safe and effective first-line treatment for hypertension, our results suggest that diuretic use in combination with a decreased renal function is associated with an increased risk at developing gout in females, and possibly needs reconsideration. Furthermore, despite the fact that the FEUa was similar distributed between genders, females did seem to have a lower urinary uric acid excretion. However, the number of patients with tophi and nephrolithiasis and the serum uric acid level are comparable between the genders. This suggests that the urate burden is similar but that the clinical profile for the development of gout differs due to the uric acid production vs excretion. In depth analysis of our population underlines the differences in female and male gout patients which highlight the need for more research into pathophysiology and management of gout between sexes.

Disclosure of Interest: None declared

DOI: 10.1136/annrheumdis-2018-eular.4488

\section{AB1044 THE EDUCATION OF PATIENTS WITH GOUT IMPROVES THE EFFECTS OF TREATMENT}

S.-J. Yoo, S.W. Kang, S.C. Shim, J. Kim, I.S. Yoo, C.K. Park. Internal Medicine, CHUNGNAM NATIONAL UNIVERSITY SCHOOL OF MEDICINE, Daejeon, Korea, Republic of Ireland

Background: The recent studies about gout demonstrated the correlation between gout and cardiovascular disease (CVD). The urate lowering therapy (ULT) ameliorates the outcomes of CVD. The poor adherence with ULT in patients with gout is the main obstacle. It is induced mainly due to a lack of adequate information about the efficacy of ULT.

Objectives: This study was performed to analyse the effects of the education for patients with gout.

Methods: 116 patients with gout were enrolled and categorised by two groups, education and non-education. The face to face education was conducted by the specially educated nurse. And all participants in two groups received an leaflet about general information of gout including lifestyle advice, nutrition and drugs of ULT. The patients in non-education group were also educated by nurse on their second visit (after two or three month from first visit). The score of patients' satisfaction using the visual analogue scale (from 0 to $100 \mathrm{~mm}$ ) and questionnaire about satisfaction and questionnaire of patients' knowledge about disease (gout) were assessed. And we analysed patients' serum uric acid level and drug compliance.

Results: A total of 116 patients were randomised to education or non-education group equally. Patients' satisfaction in visual analogue scale was significantly higher in education group (education group: $82.7 \pm 21.0 \mathrm{~mm}$, vs. non-education group: $72.8 \pm 20.7 \mathrm{~mm}, \mathrm{p}<0.001)$.

Patients' satisfaction questionnaire was significantly higher in education group (education group: $3.89 \pm 0.5$, vs. non-education group: $3.69 \pm 0.4, p=0.017$ ). The level of knowledge about gout was higher in education group (education group: $7.4 \pm 2.0$, vs. non-education group: $6.2 \pm 2.3, p=0.004)$. The serum uric acid level on second visit is decreased after education (baseline: $5.97 \pm 1.93 \mathrm{mg} / \mathrm{dL}$, vs. second visit: $5.32 \pm 1.35 \mathrm{mg} / \mathrm{dL}, \mathrm{p}=0.001)$. Besides drug compliance on second visit is improved after education (baseline: $89.6 \% \pm 16.4 \%$, vs. second visit: $94.3 \% \pm 9.9 \%$ $\mathrm{p}=0.018)$.

Conclusions: The face to face education for gout improved the patients' satisfaction, drug adherence and serum uric acid level. The education is very important part in treatment of gout.

\section{REFERENCES :}

[1] Singh JA, Strand V. Gout is associated with more comorbidities, poorer health-related quality of life and higher healthcare utilisation in US veterans. Ann Rheum Dis 2008:67:1310-6.

[2] Reesi F, Jenkins W, Doherty MPatients with gout adhere to curative treatment if informed appropriately: proof-of-concept observational study. Ann Rheum Dis 2013 72: 826-830.

[3] Cho SK, Kim D, Choi J, et al. Impact of Patient Education on the Satisfac tion of Rheumatoid Arthritis Patients: A Randomized Trial of Nurse-led Versus Medical Docter-led Education. J Rheum Dis Vol. 23, No. 2, April, 2016.

Disclosure of Interest: None declared

DOI: 10.1136/annrheumdis-2018-eular.1869

\section{AB1045 MICROPROTEINURIA AS A MARKER OF SUBCLINICAL GOUTY NEPHROPATHY}

S. Smiyan, M. Franchuk, R. Komorovsky. Internal medicine №2, I. Horbachevsky Ternopil State Medical University, Ternopil, Ukraine

Background: The prevalence of kidney damage in patients with gout ranges from $30 \%$ to $70 \%$. Currently the concept of "gouty nephropathy" (GN) comprises all renal pathologies due to gout. There is no clear opinion whether hyperuricemia is a marker of renal dysfunction or risk factor. It is important to identify the early stages of GN as its course is subclinical for a long period of time. Microproteinuria is the first harbinger of kidney damage. However, predictors of GN have not been established for today.

Objectives: To establish predictors of GN.

Methods: A total of 103 patients with chronic gouty arthritis were examined in rheumathology depatment of Ternopil University Hospital. All patients had no his tory of any kidney disease. ELISA method was used to determine microproteins in urine. Subsequently, patients were divided into 2 groups: I $(n=58)-$ patients with subclinical gouty nephropathy, abnormal microproteins level (56.3\%), II ( $n=45)-$ control group, patients without kidney damage, normal microproteins level (43.7\%). Statistical analysis was performed with STATISTICA software.

Results: Patients with subclinical gouty nephropathy had a higher prevalence of arterial hypertension and metabolic syndrome. The prevalence of osteoarthritis diabetes mellitus and dyslipidemia was the same in both groups. Also, group patients showed longer duration of the disease, greater radiologic changes, higher levels of hyperuricemia, tophi, work incapacity, greater number of affected joints and more frequent changes in urinalysis than the control group.

Conclusions: Formation of GN is asymptomatic, causing delays in early diagnosis, but can be suspended timely. Gouty nephropathy develops in $56.3 \%$ of patients with chronic gout arthritis, and manifestets by microproteinuria in the early subclinical stages. Duration of the disease, obesity, presence of tophi, arteria hypertension, hyperuricemia, increased triglycerols and low-density lipoproteins levels were found to be predictors of gouty nephropathy.

\section{REFERENCES}

[1] Singh J. A., Strand V. Gout is associated with more comorbidities, poorer health-related quality of life and higher healthcare utilisation in US veterans II Ann Rheum Dis 2008;67:1310-1316.

[2] Roddy E., Doherty M. Epidemiology of gout Arthritis Research \& Therapy 2010;12(6):223-234 